\title{
Capacitación docente en línea para atención de estudiantes universitarios con TDAH
}

Teacher Training Course Online for the Care of University Students with

$A D H D$

Treinamento on-line de professores para atenção de estudantes universitários com TDAH

Heidi Angélica Salinas Padilla

Universidad Autónoma del Carmen, Facultad de Ciencias Educativas, México salinas_heidi@yahoo.com.mx https://orcid.org/0000-0002-2260-3609

Juan José Díaz Perera

Universidad Autónoma del Carmen, Facultad de Ciencias Educativas, México jjdiaz@pampano.unacar.mx https://orcid.org/0000-0003-2098-8020

Gabriela Guadalupe Montiel Cantarell

Universidad Autónoma del Carmen, Facultad de Ciencias Educativas, México gabi.gpe.montiel@hotmail.com https://orcid.org/0000-0003-4228-4614 


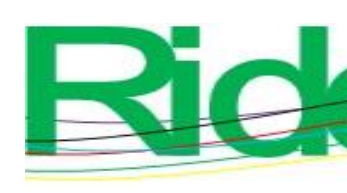

Revista Iberoamericana para la Investigación y el Desarrollo Educativo ISSN $2007-7467$

\section{Resumen}

El propósito del presente estudio fue evaluar el impacto de una capacitación docente diseñada en un ambiente virtual de aprendizaje que tiene como meta proveer a los docentes de la Universidad Autónoma del Carmen (Unacar) de los conocimientos necesarios para atender a los alumnos que padecen trastorno por déficit de atención con hiperactividad (TDAH). Se realizó una investigación de tipo correlacional, con un diseño de tipo cuasi experimental de un solo grupo con pre y postest, transeccional. Teniendo una población de 227 profesores de tiempo completo, la muestra se conformó de 25 docentes pertenecientes a todas las dependencias de educación que integran la institución; la selección fue no probabilística. El instrumento para la recolección de datos fue un cuestionario que buscó conocer el nivel de actitud de los docentes. Se desarrolló un análisis por puntaje y, para probar si existió un incremento significativo en la actitud, se realizó la prueba $t$ de Student entre la fase pre y postest. Los resultados obtenidos reflejan un incremento significativo por parte de los docentes en la actitud de inclusión hacia los estudiantes con TDAH y una mayor atención en la diversidad en el aula.

Palabras clave: diseño instruccional, profesionalización docente, TDAH.

\section{Abstract}

The purpose of this study was to evaluate the impact of a teacher training designed in a virtual learning environment, which aims to provide teachers at the Autonomous University of Carmen (UNACAR) with the necessary knowledge to serve university students who suffer from attention deficit hyperactivity disorder (ADHD). A correlational investigation was carried out, with a quasi-experimental design of a single group with pre- and post-test, transectional. The population is 227 full-time teachers and the sample was made up of 25 teachers belonging to all the education units that make up the institution; the selection was not probabilistic. The instrument for data collection was a questionnaire that sought to know the level of attitude of teachers. The analysis of the results of the attitude level instrument was developed by analysis by score, to test if there was a significant increase in attitude through the $t$-test between the pre- and post-test phase. The results obtained in relation to the level of teacher attitude towards university students with ADHD reflect a significant increase in the attitude of inclusion and attention to diversity in the classroom.

Keywords: instructional design, teacher professionalization, ADHD. 


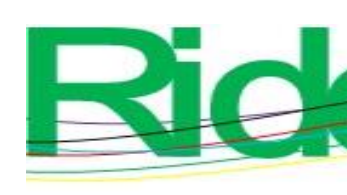

Revista Iberoamericana para la Investigación y el Desarrollo Educativo ISSN $2007-7467$

\section{Resumo}

O objetivo deste estudo foi avaliar o impacto de uma formação de professores projetada em um ambiente virtual de aprendizagem que visa proporcionar aos professores da Universidade Autônoma de Carmen (Unacar) o conhecimento necessário para atender os alunos que sofrem de transtorno de déficit de atenção e hiperatividade (TDAH). Foi realizada uma pesquisa correlacional, com desenho quase experimental de um único grupo com pré e pós-teste, transecional. Com uma população de 227 professores em período integral, a amostra foi composta por 25 professores pertencentes a todas as unidades de ensino que compõem a instituição; a seleção foi não probabilística. $\mathrm{O}$ instrumento de coleta de dados foi um questionário que buscou conhecer o nível de atitude dos professores. Uma análise de pontuação foi desenvolvida e, para testar se havia um aumento significativo de atitude, o teste $t$ de Student foi realizado entre a fase pré e pós-teste. Os resultados obtidos refletem um aumento significativo dos professores na atitude de inclusão em relação aos alunos com TDAH e maior atenção à diversidade na sala de aula.

Palavras-chave: desenho instrucional, profissionalização de professores, TDAH.

Fecha Recepción: Octubre 2019

Fecha Aceptación: Marzo 2020

\section{Introducción}

Las políticas internacionales y nacionales en materia de inclusión educativa han impulsado el desarrollo de nuevos modelos educativos que ofrezcan calidad, equidad e inclusión: una educación para todos. En el presente documento se aborda un curso de capacitación docente desarrollado en un ambiente virtual de aprendizaje cuyo objetivo fue promover en los docentes de la Universidad Autónoma del Carmen (Unacar) las competencias necesarias para brindarle atención a estudiantes universitarios diagnosticados con el trastorno por déficit de atención con hiperactividad (TDAH). Para ello se presentó la propuesta de capacitación al Departamento de Superación Académica, encargado de atender las acciones de inclusión educativa en el nivel superior como parte de las estrategias que se están desarrollando en la universidad en el marco del Plan de Desarrollo Institucional 2017 - 2021 (Unacar, 2018b).

El presente documento se organiza en los apartados de antecedentes y justificación, diseño del estudio, población y objeto de estudio, instrumento, resultados, discusión y conclusiones. La importancia del tema no solo reside en el hecho de la capacitación, sino en 


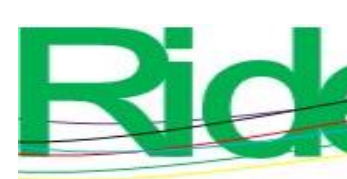

Revista Iberoamericana para la
Investigación y el Desarrollo Educativo
ISSN $2007-7467$

la necesidad de realizar una evaluación del proceso de capacitación docente en lo que refiere al TDAH. Por lo que se desarrolló una investigación de tipo correlacional con un diseño de cuasi experimento. El universo de estudio fue de 227 profesores de tiempo completo y la muestra no probabilística determinada fue de 25 docentes adscritos en las diferentes facultades de la Unacar. Para la recolección de datos sobre el nivel de actitud de los docentes, se utilizó un cuestionario y el análisis de los resultados sobre el nivel de actitud fue desarrollado por puntaje. El incremento significativo de la actitud de los docentes se midió con la prueba $t$ de Student en la fases de pre y postest, con el propósito de evaluar el impacto de la capacitación.

\section{Antecedentes y justificación}

Desde la década de los 90, la temática de integración y posteriormente inclusión educativa ha estado presente en la discusión nacional en México y ha posibilitado no solo implementar una serie de medidas para hacer realidad el principio de derecho a la educación, sino también introducir un conjunto de normativas legales y orientaciones pedagógicas para ir mejorando las primeras experiencias de los estudiantes con necesidades educativas especiales en el ámbito educativo. En las últimas décadas, el sistema educativo mexicano ha estado inmerso en constantes cambios, desde la currícula que plantea el discurso de inclusión educativa hasta lo que se refiere a la formación y capacitación de la planta docente. Las instituciones educativas, de todos los niveles, atendiendo a la política de inclusión, reciben a estudiantes con una amplia diversidad de características. Algunos de ellos cuentan con un diagnóstico de necesidad educativa especial o lo reciben durante su proceso de formación. Frente a tal escenario, los profesores, en muchos casos, presentan dificultades para hacer que el alumno adquiera los aprendizajes necesarios para la vida.

Para tener un mayor panorama de la situación, es importante hacer referencia al Censo 2010 del Instituto Nacional de Estadística y Geografía (Inegi), el cual calcula que, en ese entonces, en México había 5739270 personas con alguna dificultad física o mental para realizar actividades de la vida cotidiana (Secretaría de Educación Pública [SEP], 2012). Esto es realmente preocupante si se toma en cuenta que, del total de estas personas registradas con alguna dificultad física o mental, solo se atendieron algunas necesidades educativas. De tal forma que resulta evidente que las estrategias que ha implementado el 

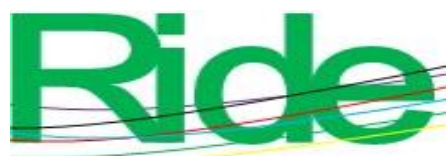

Revista Iberoamericana para la Investigación y el Desarrollo Educativo ISSN 2007 - 7467

Gobierno no han sido suficientes para la atención de este sector de la población (ver figura $1)$.

Figura 1. Total de alumnos que son atendidos por necesidad educativa especial en México

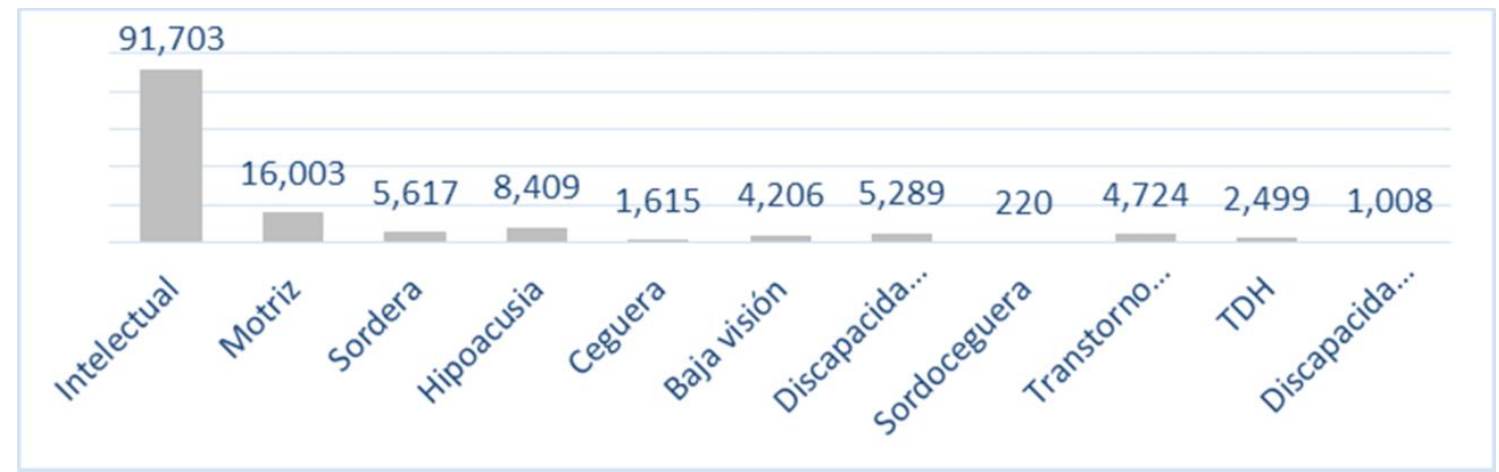

Fuente: SEP (2012)

En la figura 1 se puede apreciar que los alumnos que son atendidos por necesidad educativa especial en México representan menos de $5 \%$ del total de personas con alguna necesidad especial. Lo anterior deja al descubierto varios factores: la atención insuficiente por parte de las autoridades correspondientes, así como que los docentes no están aplicando metodologías o no buscan los recursos necesarios o los recursos que se han implementado no cubren todas las escuelas.

Enfocando más esta problemática hacia Campeche, se tiene como dato que en 2012 había un total de 1646 escuelas de educación básica regular en todo el estado, de las cuales solo 253 contaban con el apoyo de algún servicio de educación especial, ya sea los Centros de Atención Psicopedagógico de Educación Preescolar (Capep), Centros de Recursos e Información para la Integración Educativa (CRIE) o las Unidades de Servicio de Apoyo a la Educación Regular (Usaer) (SEP, 2012) (ver tabla 1). 


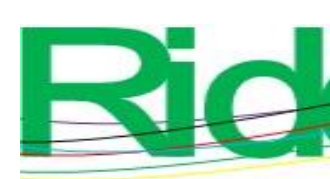

Revista Iberoamericana para la Investigación y el Desarrollo Educativo ISSN 2007 - 7467

Tabla 1. Total de escuelas de educación básica regular que en 2012 contaban con apoyo de algún servicio de educación especial

\begin{tabular}{|l|l|l|l|}
\hline Entidades & $\begin{array}{l}\text { Total escuelas de } \\
\text { educación básica } \\
\text { regular por entidad }\end{array}$ & $\begin{array}{l}\text { Total de escuelas } \\
\text { de educación básica } \\
\text { regular con algún } \\
\text { servicio de } \\
\text { educación especial }\end{array}$ & $\begin{array}{l}\text { Porcentaje de } \\
\text { cobertura }\end{array}$ \\
\hline Aguascalientes & 1429 & 521 & $36 \%$ \\
\hline Baja California & 2741 & 836 & $30 \%$ \\
\hline Baja California Sur & 792 & 262 & $33 \%$ \\
\hline Campeche & 1646 & 253 & $15 \%$ \\
\hline
\end{tabular}

Fuente: SEP (2012)

Para respaldar los datos anteriores se encontró que en el estado de Campeche solo hay cinco CRIE, muestra del poco apoyo que existe para la educación especial (véase tabla 2).

Tabla 2. Total de CRIE en Campeche en comparación con otros estados

\begin{tabular}{|l|l|}
\hline Entidades & CRIE \\
\hline Aguascalientes & 7 \\
\hline $\begin{array}{l}\text { Baja } \\
\text { California }\end{array}$ & 6 \\
\hline $\begin{array}{l}\text { Baja } \\
\text { California Sur }\end{array}$ & 4 \\
\hline Campeche & 5 \\
\hline
\end{tabular}

Fuente: SEP (2012)

Por otro lado, aún no es posible contar con información sistematizada y actualizada a nivel media superior y superior que refleje la realidad nacional en este ámbito: cuántos alumnos con dichas necesidad estudian en instituciones a ese nivel, a cuáles carreras tienen acceso y cuáles son las condiciones que acompañan su andar educativo. Es una realidad que cada vez son más los casos que se presentan en la educación básica, y la educación media superior y superior debe posibilitar el ingreso de las personas con necesidades educativas 


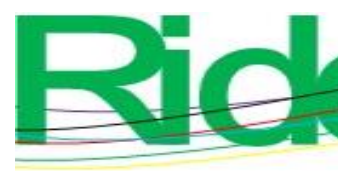

Revista Iberoamericana para la
Investigación y el Desarrollo Educativo
ISSN $2007-7467$

especiales y realizar las adecuaciones necesarias en los procesos de enseñanza-aprendizaje para que puedan acceder a las diferentes carreras.

Ahora bien, como parte de los antecedentes identificados en la institución objeto de estudio, Herrera, Guzmán, Salinas, Sánchez y Díaz (2018) se plantearon como objetivo principal conocer, desde la perspectiva de los estudiantes de la Facultad de Ciencias Educativas, la opinión de estos sobre la Unacar como institución que promueve la inclusión educativa. Para ello utilizaron un instrumento con escala de Likert. La información que obtuvieron les permitió concluir que esta institución ha implementado estrategias diversas para atender la promoción de valores; sin embargo, mencionan que, a pesar de los años, de las metas, certificaciones, acreditaciones alcanzadas, falta aún consolidar programas de apoyo académico pensados para estudiantes con necesidades especiales, programas que estén acorde y alineados a las actuales reformas educativas. Por último, en lo referente a la igualdad de oportunidades, recomiendan incrementar las estrategias de concientización dirigidas a toda la comunidad universitaria y contar con una actualización constante de los docentes para brindar un servicio igualitario y de calidad a los estudiantes con condiciones de vida diferentes y así lograr una educación para la diversidad.

Es así que se genera la propuesta de capacitación docente para la atención de alumnos con TDAH; una capacitación que, ante los avances tecnológicos que han ocurrido en los último años, se plantea desde una perspectiva flexible y con la capacidad de adaptarse a las necesidades de los docentes (García, Jaña, y Yáñez 2019). Como menciona Vergara (2007):

[Las tecnologías de la información y la comunicación (TIC)] han permitido concretar la flexibilización de programas y cursos a distancias, en especial a través del e-learning, que ha facilitado la interacción, el acceso a la información y otras características que la educación a distancia de las primeras generaciones no lograba satisfacer (p. 112).

El e-learning o los ambientes virtuales de aprendizaje se han utilizado para la formación de personas adultas. Y de acuerdo con trabajos consultados en el uso de esta modalidad para dar capacitación, como los realizados por García, Jaña y Yáñez en el 2019 y el de Vergara en el 2007, es factible llevar a cabo el curso en atención de las necesidades educativas especiales a través de un ambiente virtual de aprendizaje. 


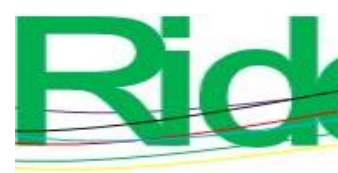

Revista Iberoamericana para la Investigación y el Desarrollo Educativo ISSN $2007-7467$

Es necesario buscar que el docente replantee su quehacer docente y desarrolle habilidades que interioricen el concepto de inclusión educativa y que respondan a la atención de alumnos diagnosticados con TDAH.

Teniendo en cuenta lo anterior, se planteó la propuesta de un curso de capacitación en un ambiente virtual de aprendizaje que impacte de manera significativa en los conocimientos que tiene el docente en relación con la inclusión, y en particular con el TDAH. La capacitación en un ambiente virtual de aprendizaje será una herramienta para los docentes que se encuentren sumergidos en la educación formal de nivel media superior y superior: les permitirá capacitarse, de manera flexible y acorde al contexto en el que se encuentren, para desarrollar aún más su sentido de inclusión.

La premisa del Modelo Educativo Acalán de la Unacar (2018a), en su carácter de bien público social, se ratifica mediante el compromiso institucional de que todos los ciudadanos tengan acceso a sus programas, tal y como lo considera el Plan de Desarrollo Institucional 2017 - 2021 (Unacar, 2018b). Con un modelo centrado en el aprendizaje de sus estudiantes y con un enfoque por competencias, la Unacar pone en relieve su compromiso social: ubicar en el centro de todos los procesos de enseñanza-aprendizaje los problemas, necesidades y cambio sociales con los que necesariamente tienen que interactuar los estudiantes para aprender (Unacar, 2018a). De este modo, genera las condiciones necesarias que favorecen el acceso a una educación media superior y superior de calidad, mediante estrategias y acciones consecuentes.

Una vez dicho todo lo anterior, se plantean los siguientes objetivos:

- Realizar el diseño instruccional del curso en un ambiente virtual de aprendizaje sobre la inclusión y el TDAH.

- Conocer el nivel de satisfacción sobre el curso de capacitación en un ambiente virtual de aprendizaje.

\section{Diseño del estudio}

El presente estudio tuvo como propósito evaluar el impacto de una capacitación docente diseñada en un ambiente virtual de aprendizaje y puesta en marcha en la Unacar. El modelo propuesto de la investigación es correlacional, de acuerdo con Hernández, Fernández y Baptista (2010), quienes mencionan que en este tipo de investigación se usa la recolección de datos para probar hipótesis, con base en la medición numérica y el análisis 


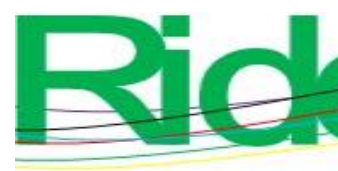

Revista Iberoamericana para la
Investigación y el Desarrollo Educativo
ISSN $2007-7467$

estadístico, para establecer patrones de comportamiento y probar teorías. Se le denomina de esta manera ya que tiene como finalidad conocer la relación o grado de asociación que existe entre dos o más variables en un contexto particular. En este caso, la variable dependiente fue la actitud de los docentes y la variable independiente el diseño instruccional del curso en el contexto de la universidad ya especificada.

Tiene un diseño de tipo cuasi experimental. Al respecto, Hernández et al. (2010) mencionan que recibe esta denominación porque se manipula una variable independiente para observar su efecto en relación con una o más variables dependientes. También comentan que es un conjunto de procedimientos o estrategias de investigación orientado a la evaluación del impacto de los tratamientos y, por lo tanto, permite un número de participantes reducido por grupo de capacitación para docentes.

El diseño de la investigación es de un solo grupo con pre y postest. El efecto se comprueba comparando uno y otro. Este diseño sirve para estudiar las variaciones en determinadas variables que cambiarían si se intervinieran. Una vez más, para Hernández et al. (2010) los diseños de investigación transeccional o transversal recolectan datos en un solo momento, en un tiempo único. Su propósito es describir variables y analizar su interrelación en un momento dado. Para esta investigación se tomó un grupo único.

\section{Población objeto de estudio}

La institución objeto de estudio imparte educación de nivel medio superior y superior. Tiene 227 profesores de tiempo completo contratados, quienes dentro de sus funciones atienden actividades de docencia, investigación, gestión y tutorías. De esta cifra, 207 cuentan con estudios de posgrado, 177 con doctorado de carácter disciplinar.

La muestra identificada fue de 41 docentes pertenecientes a todas las dependencias de educación que integran la Unacar. Los criterios de inclusión de los participantes fueron los de ser profesores de la universidad y estar activos.

Los criterios de exclusión fueron, en primer lugar, aquellos que no quisieran participar; en segundo lugar, se utilizó el de incumplimiento de la prueba pretest; y por último, aquellos docentes que iniciaron la capacitación y no la terminaron. De esta manera, la muestra quedó compuesta por 25 participantes. 


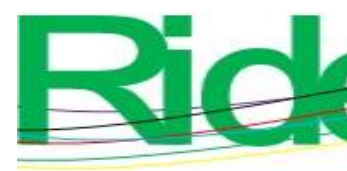

Revista Iberoamericana para la Investigación y el Desarrollo Educativo ISSN $2007-7467$

El curso de capacitación tuvo como objetivo desarrollar competencias en los docentes que integren y favorezcan la participación y aprendizaje de sus alumnos diagnosticados con el TDAH, fortaleciendo actitudes y disposiciones favorables para promover transformaciones en las prácticas educativas. Fue organizado en cuatro módulos. El primer módulo refiere a la introducción de conocimiento sobre la inclusión y atención a la diversidad; el módulo dos aborda la normatividad sobre la inclusión en México; el tercer módulo pretendió fortalecer actitudes y disposiciones para promover transformaciones en la práctica educativa; en el cuarto módulo se abarca información sobre el TDAH.

El segundo instrumento se refiere al aspecto actitudinal de la inclusión y el TDAH, la operacionalización del nivel de actitud, determinada por cinco alternativas de respuestas correspondientes a la escala Likert; aquí se manejaron las mismas dimensiones. Se aplicó de forma posterior al curso. En él se plantearon tres niveles de respuestas en relación con la actitud. Si bien varía la puntuación de acuerdo con la dimensión, de igual manera se categoriza una puntuación para una actitud adecuada, parcialmente adecuada e inadecuada. Los primeros dos instrumentos fueron validados a juicio de dos expertos, a saber: la psicóloga clínica Reina del Carmen Tello Briceño y el Mtro. Juan José Díaz Perera, experto en diseño de instrumentos de investigación.

De igual forma, se realizó una validación por constructo, la cual se sometió, a su vez, a dos revisiones; una vez realizado esto, quedaron listos los instrumentos para el pilotaje y para poder realizar la confiabilidad. La confiabilidad de los instrumentos se desarrolló mediante un pilotaje del instrumento con una muestra de 18 docentes de educación básica, dado que la propuesta de capacitación sobre el tema TDAH fue diseñado en primera instancia para los profesores de ese nivel. Sin embargo, ante el Plan de Desarrollo Institucional (Unacar, 2018b) y sus ejes rectores, el Departamento de Superación Académica analizó la propuesta de capacitación y su concordancia con el tema de educación inclusiva en la educación superior y dictaminó la pertinencia del curso con su diseño original y autorizó desarrollar la capacitación con los profesores de nivel superior, considerando que favorece la sensibilización de los docentes para atender la inclusión en las aulas universitarias. La confiabilidad del cuestionario fue mediante la prueba alfa de Cronbach y para la encuesta tipo escala de Likert con la prueba de Kuder-Richardson 20, conocida como KR20. 

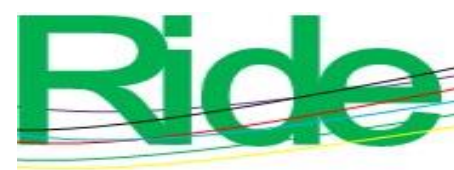

Revista Iberoamericana para la Investigación y el Desarrollo Educativo ISSN 2007 - 7467

Dos características deseables en toda medición son la confiabilidad y la validez. Al referirse a cualquier instrumento de medición en el campo de las ciencias sociales y de la conducta, se consideran estas dos cualidades como aspectos claves de la llamada solidez psicométrica del instrumento (Sierra, Negron y Santoyo, 2017).

En el alfa de Cronbach, la descripción resultante de los ítems o reactivos es resumida con el término homogeneidad: el grado en que una prueba o instrumento mide un solo factor, es decir, el grado en que los reactivos en una escala son unifactoriales. Más precisamente, el coeficiente de consistencia interna dependerá directamente de las correlaciones entre los ítems o reactivos, esto es, del grado en que los ítems midan la misma variable. Mientras más homogéneos sean los ítems, mayor será el valor de la consistencia interna para un número dado de ítems (Muñiz y Fonseca, 2019).

Los investigadores Carmines y Zeller (1979, citados en Quero, 2010) consideran que, como regla general, las confiabilidades no deben ser inferiores a 0.80 . Teniendo en cuenta lo anterior, aquí se alcanzó un rango aceptable, pues se obtuvo una confiabilidad del instrumento escala de Likert de 0.944.

\section{Resultados}

En cuanto a los resultados de la variable que refiere a la actitud que tiene el docente en relación con la dimensión sobre la inclusión y atención a la diversidad en el aula en la fase de pretest, se observa que $36 \%$ de los docentes mantienen una actitud adecuada sobre el tema (véase figura 2). 


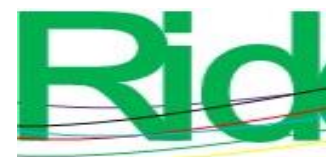

Revista Iberoamericana para la Investigación y el Desarrollo Educativo ISSN $2007-7467$

Figura 2. Actitud de los docentes sobre la inclusión y atención a la diversidad en el aula

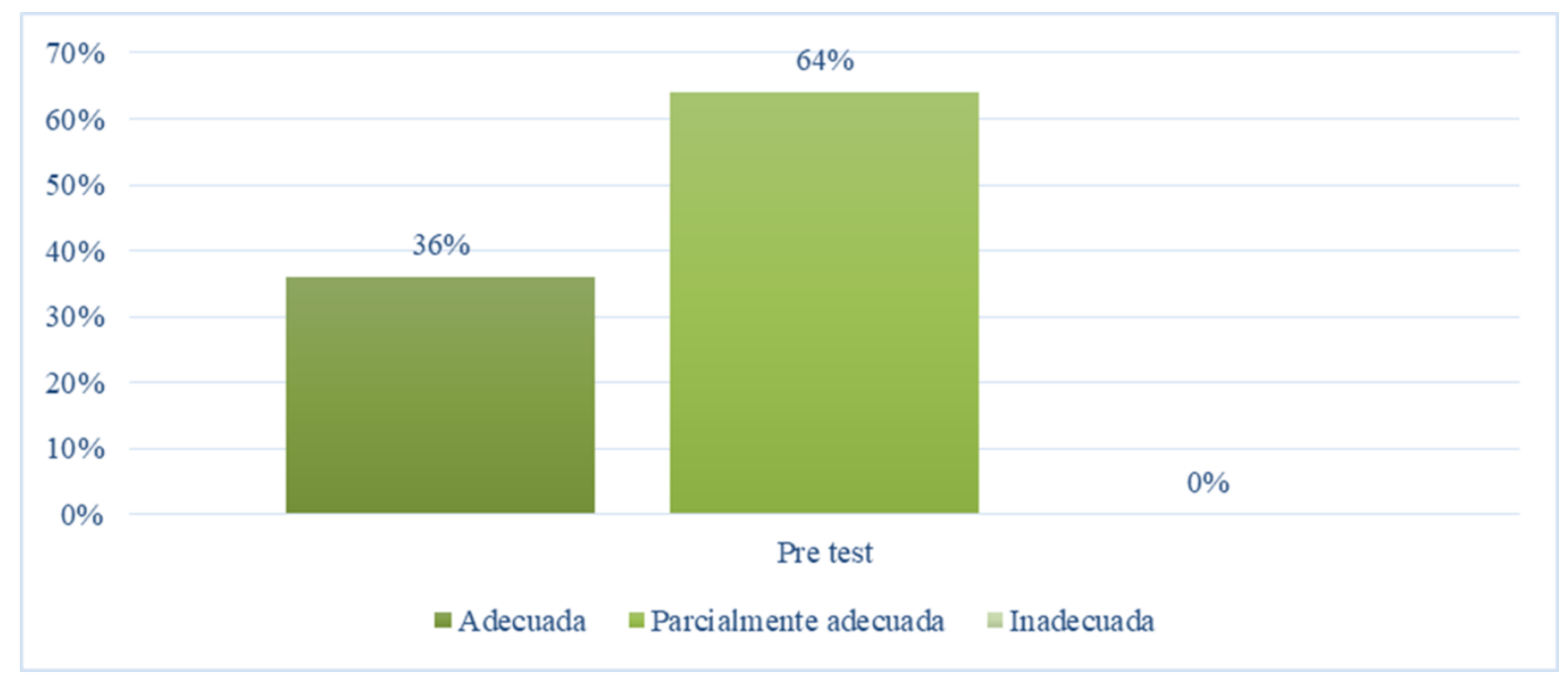

Fuente: Elaboración propia

También se realizó un análisis de la actitud en la dimensión sobre el marco normativo de la inclusión educativa: $32 \%$ de los docentes tienen una actitud adecuada al respecto (véase figura 3 ).

Figura 3. Actitud de los docentes sobre el marco normativo de la inclusión educativa

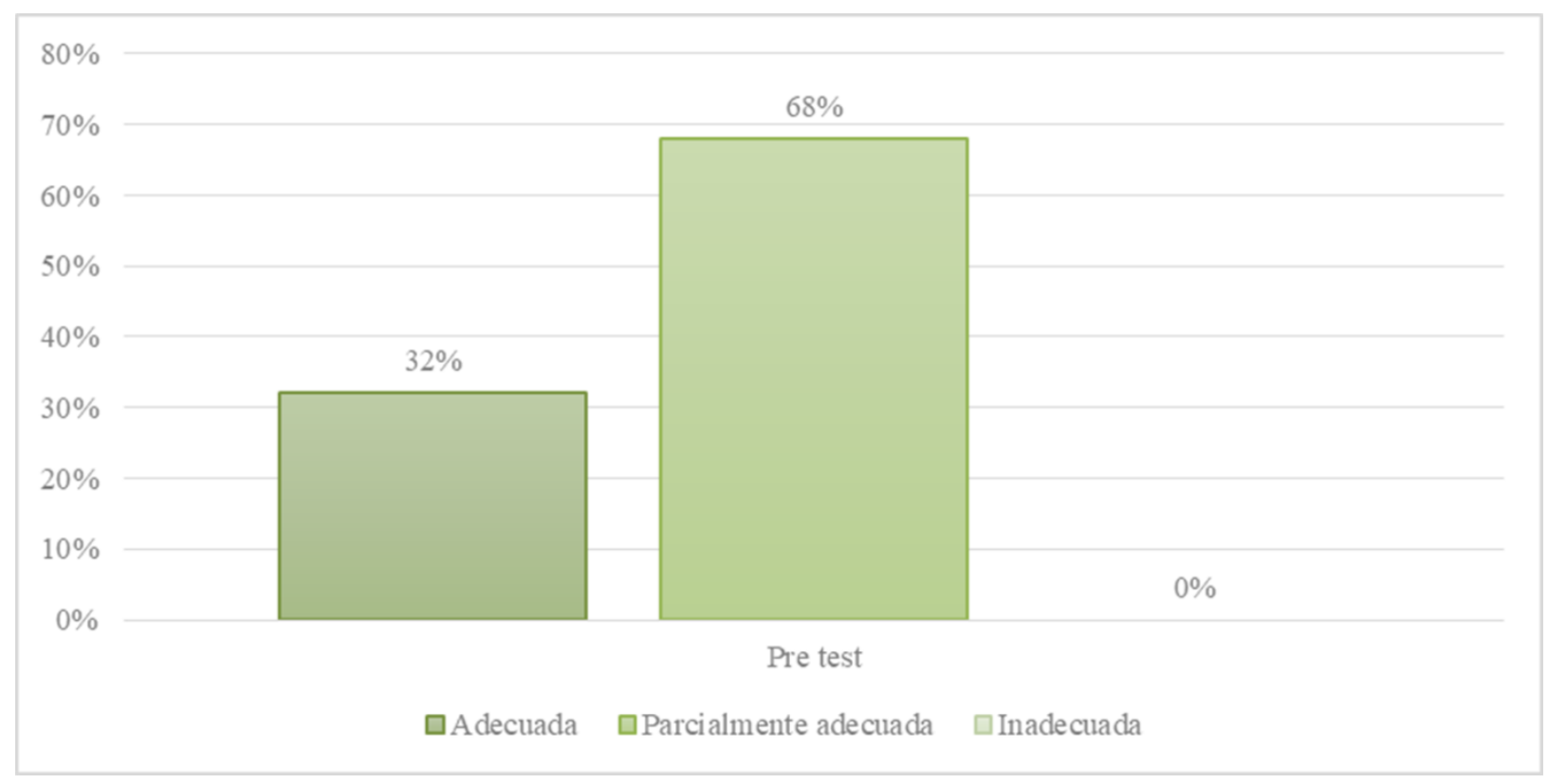

Fuente: Elaboración propia 

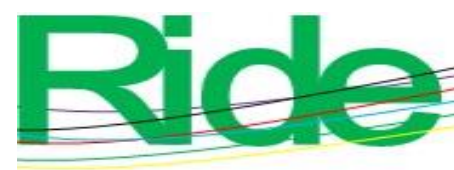

Revista Iberoamericana para la Investigación y el Desarrollo Educativo ISSN $2007-7467$

A continuación se presentan los resultados de la misma variable, pero en relación con el TDAH. Así, se obtuvo como resultado que solo 4 \% de los docentes tenía una actitud adecuada, mientras que $72 \%$ una actitud parcialmente adecuada (ver figura 4).

Figura 4. Actitud de los docentes sobre el TDAH

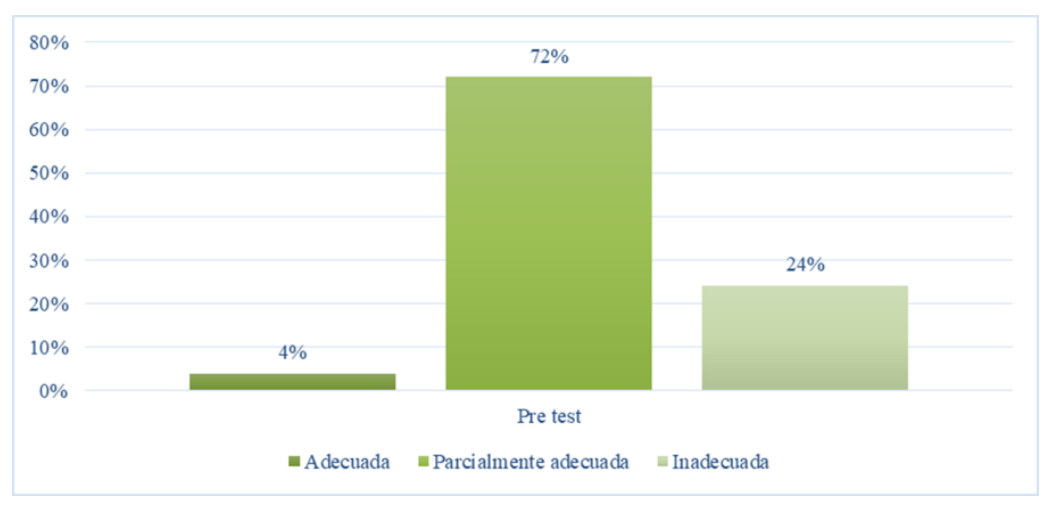

Fuente: Elaboración propia

En contraste, los resultados del postest en cuanto a la variable de actitud del docente en la inclusión y atención a la diversidad en el aula muestran que hubo un incremento: ahora $56 \%$ de los docentes tiene una actitud adecuada.

Como se mencionó líneas atrás, el objetivo de este estudio es conocer el nivel de actitud de los docentes en relación a los alumnos con TDAH. Para llegar a una respuesta, se realizó el análisis de los resultados del instrumento de nivel de actitud; se aplicó un análisis por puntaje para probar si existió un incremento significativo en la actitud mediante la prueba $t$ Student entre la fase pre y pos de los 25 integrantes de la muestra del estudio.

En esta se encuentra que el valor de significancia es menor a $0.05(0.000<0.05)$, por lo que se acepta que hay una diferencia significativa en las medias de los resultados antes y después del curso de capacitación en un ambiente virtual de aprendizaje en la actitud del docente a un nivel de confiabilidad de $95 \%$. 


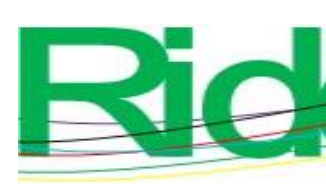

Revista Iberoamericana para la Investigación y el Desarrollo Educativo ISSN $2007-7467$

Tabla 4. Estadística descriptiva del pre y postest de la variable de la actitud

\begin{tabular}{|l|l|l|l|l|l|}
\hline & & Media & N & $\begin{array}{l}\text { Desviación } \\
\text { estándar }\end{array}$ & $\begin{array}{l}\text { Media de } \\
\text { error } \\
\text { estándar }\end{array}$ \\
\hline Part 1 & Pretest & 6.52 & 25 & 1.122 & 0.224 \\
\hline & Postest & 7.92 & 25 & 0.862 & 0.172 \\
\hline
\end{tabular}

Nota: $\mathrm{N}=$ Número de participantes en el estudio.

Fuente: Elaboración propia

Asimismo, para determinar si la diferencia existente es significativa entre las fases de pre y postest, se analizaron, mediante la $t$ Student unilateral, los resultados, y se obtuvo que la posprueba es mayor en este aspecto que el pretest (tabla 5).

Tabla 5. Prueba de muestras emparejadas $t$ de Student del pre y postest en relación con la actitud

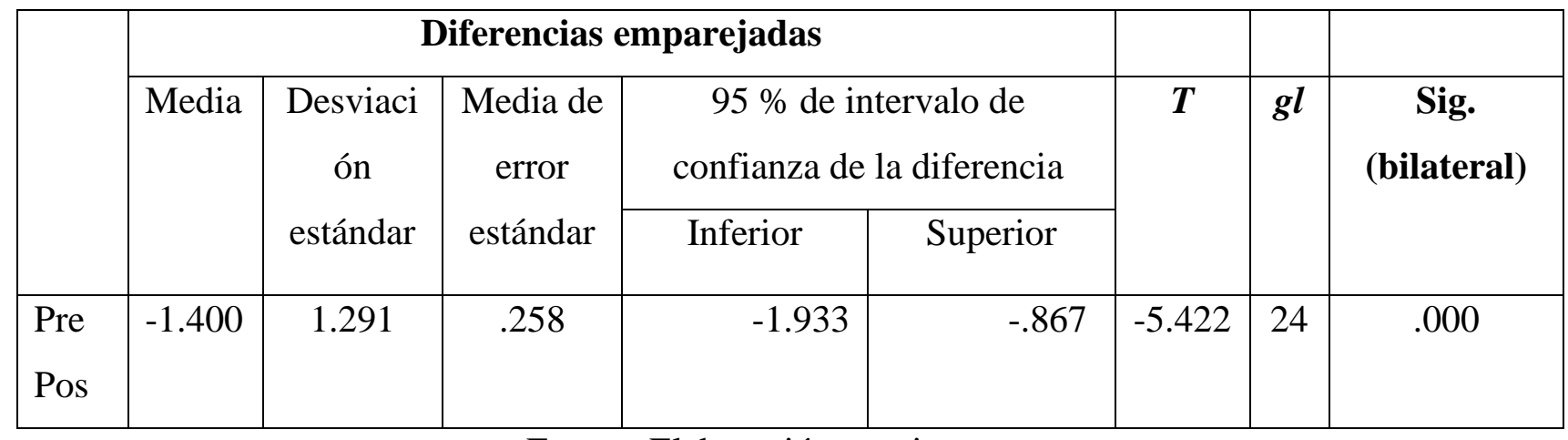

Fuente: Elaboración propia

Por lo cual se concluye que el curso de capacitación en un ambiente virtual de aprendizaje sí tiene efectos significativos sobre el conocimiento y la actitud de los docentes en relación con los alumnos con TDAH.

En cuanto a la variable independiente, que hace referencia al curso de capacitación "Hablemos de Inclusión y Conozcamos sobre el Trastorno por Déficit de Atención e Hiperactividad " en un ambiente virtual de aprendizaje, se obtuvo la valoración de 25 docentes que tomaron la capacitación en relación con la presentación del programa de la materia de forma completa. De ellos, $80 \%$ estuvo de acuerdo y muy de acuerdo (figura 5). 

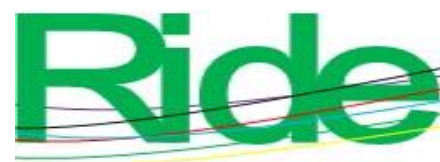

Revista Iberoamericana para la Investigación y el Desarrollo Educativo ISSN $2007-7467$

Figura 5. Percepción de los docentes de la presentación de capacitación

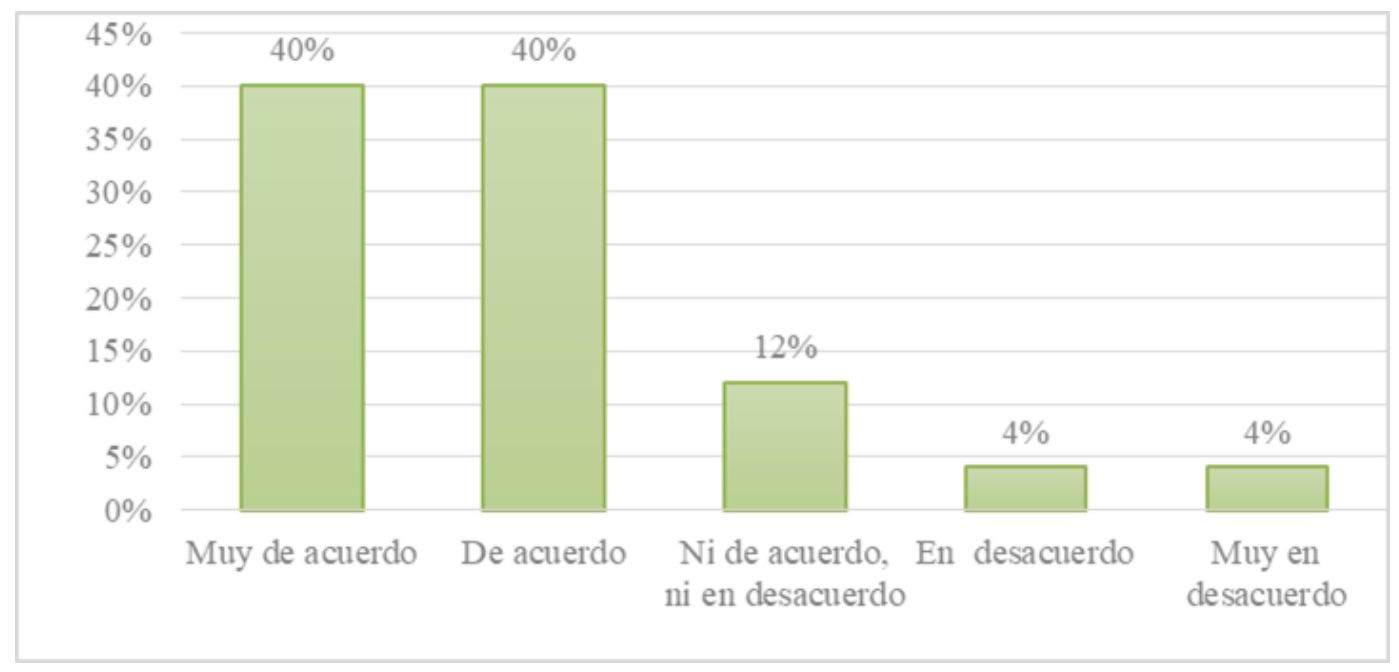

Fuente: Elaboración propia

En relación con la metodología del trabajo presentada en tiempo y forma por el facilitador del curso, $84 \%$ de los docentes expresaron una opinión favorable, mientras que $16 \%$ expresó estar en desacuerdo (figura 6).

Figura 6. Metodología del trabajo

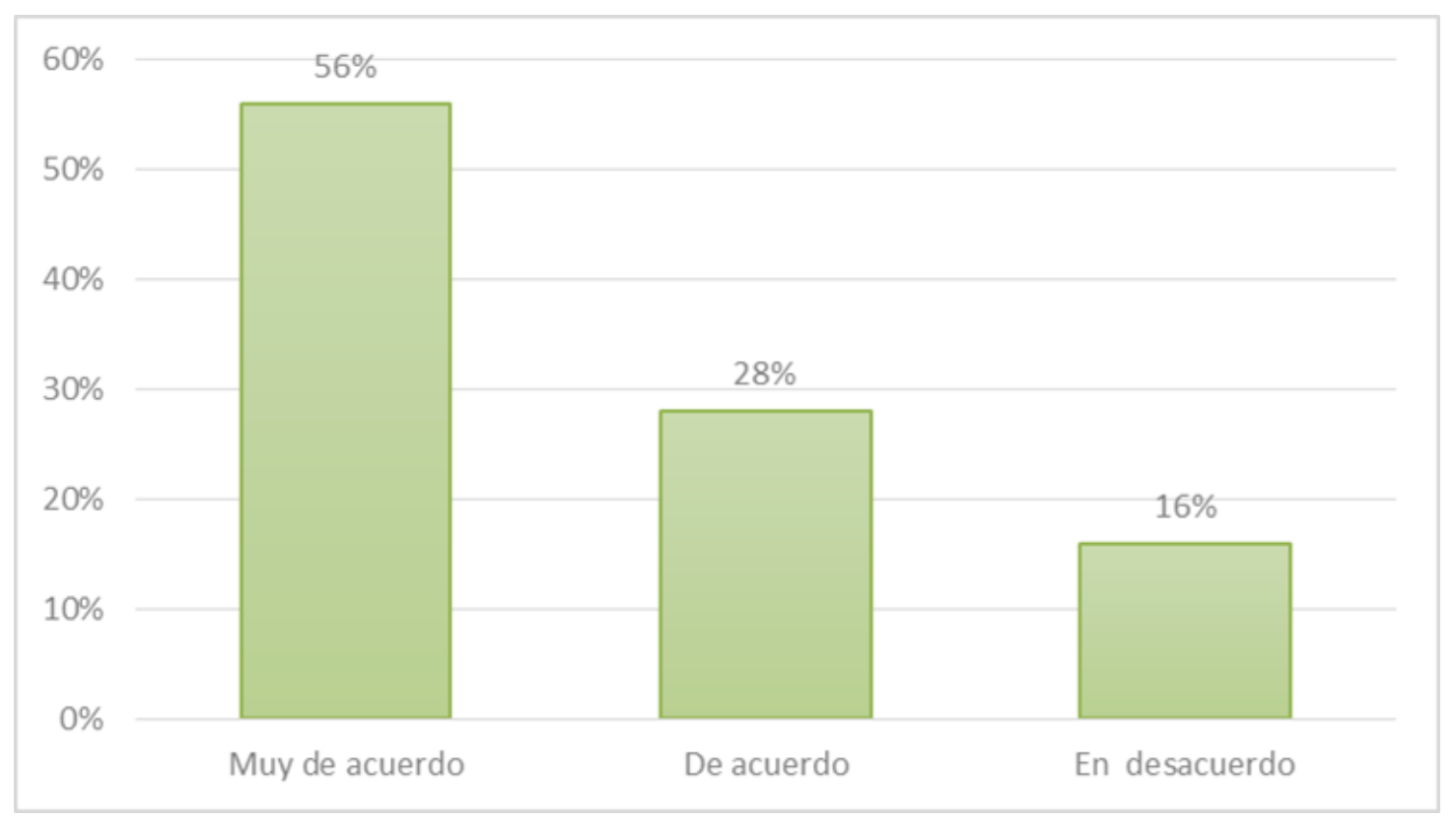

Fuente: Elaboración propia

En correspondencia al cumplimiento de los objetivos de aprendizaje del curso, $84 \%$ de los participantes consideró que en el desarrollo del curso se cumplieron los objetivos planteados, mientras que $16 \%$ expresó estar en desacuerdo y muy en desacuerdo (ver figura 7). 
Figura 7. Percepción del docente sobre el cumplimiento de los objetivos de aprendizaje planteados en el curso de capacitación

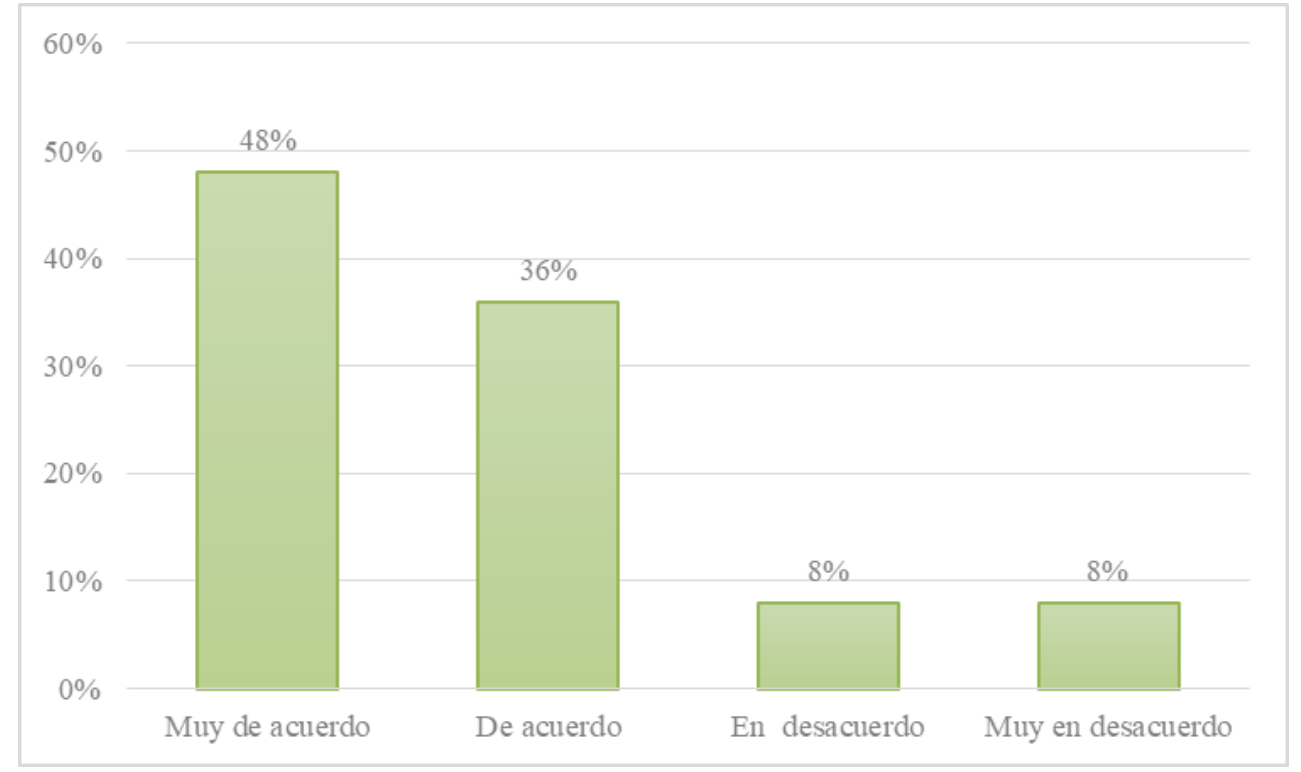

Fuente: Elaboración propia

La interacción entre participantes en el ambiente virtual de aprendizaje que permitiera la colaboración y cooperación entre los tutores participantes del curso fue considerada por $84 \%$ como buena. Se observa, también, que $12 \%$ consideró no estar de acuerdo ni en desacuerdo con lo planteado (ver figura 8).

Figura 8. Interacción entre los participantes

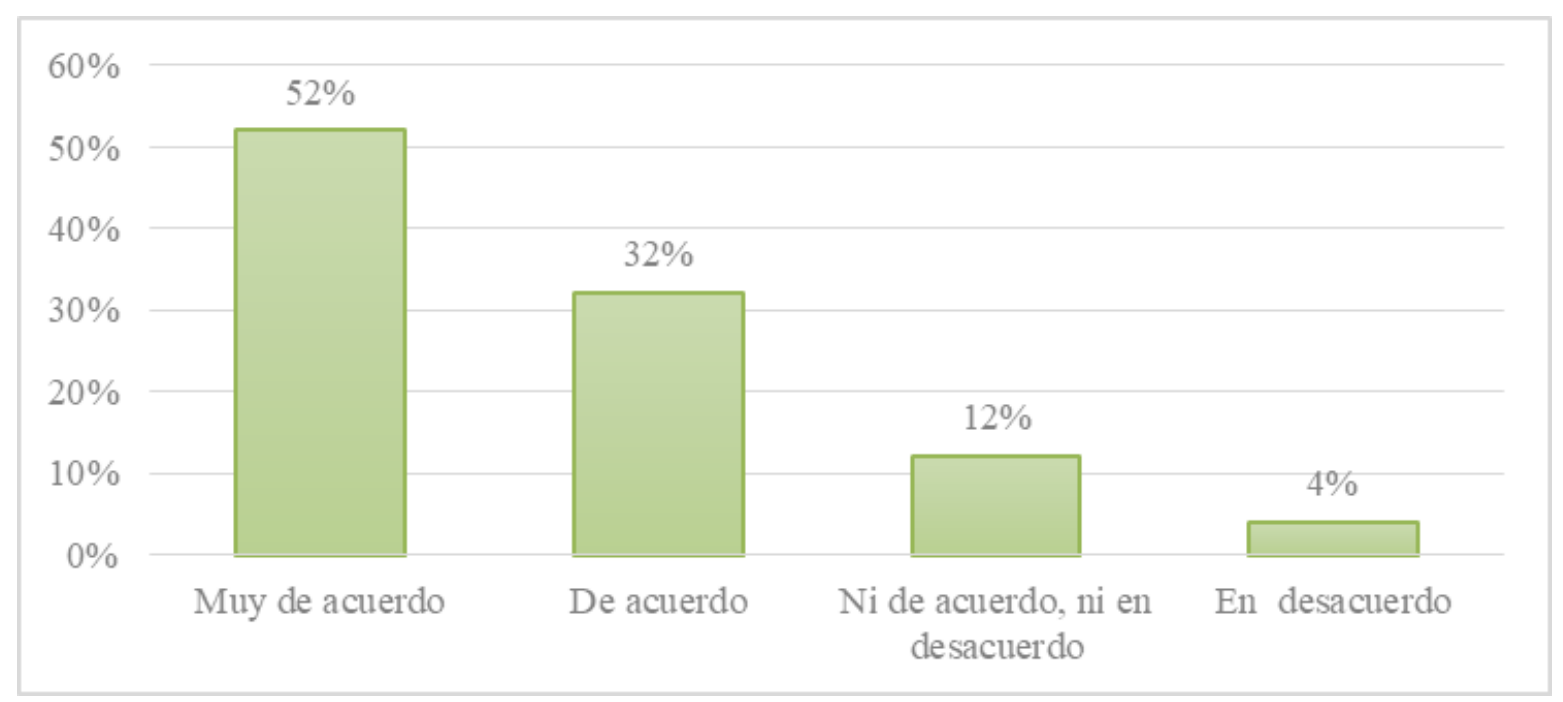

Fuente: Elaboración propia 

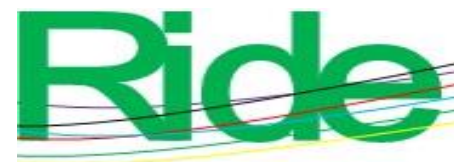

Revista Iberoamericana para la
yestigación el Desarrollo Educativo

Por su parte, $76 \%$ consideró favorables los materiales utilizados en el curso, tales como textos, vídeos, hipertextos, ya que estos apoyaron en el logro de los objetivos de aprendizaje (figura 9).

Figura 9. Percepción de los docentes sobre el apoyo de los materiales en el logro de los objetivos de aprendizaje

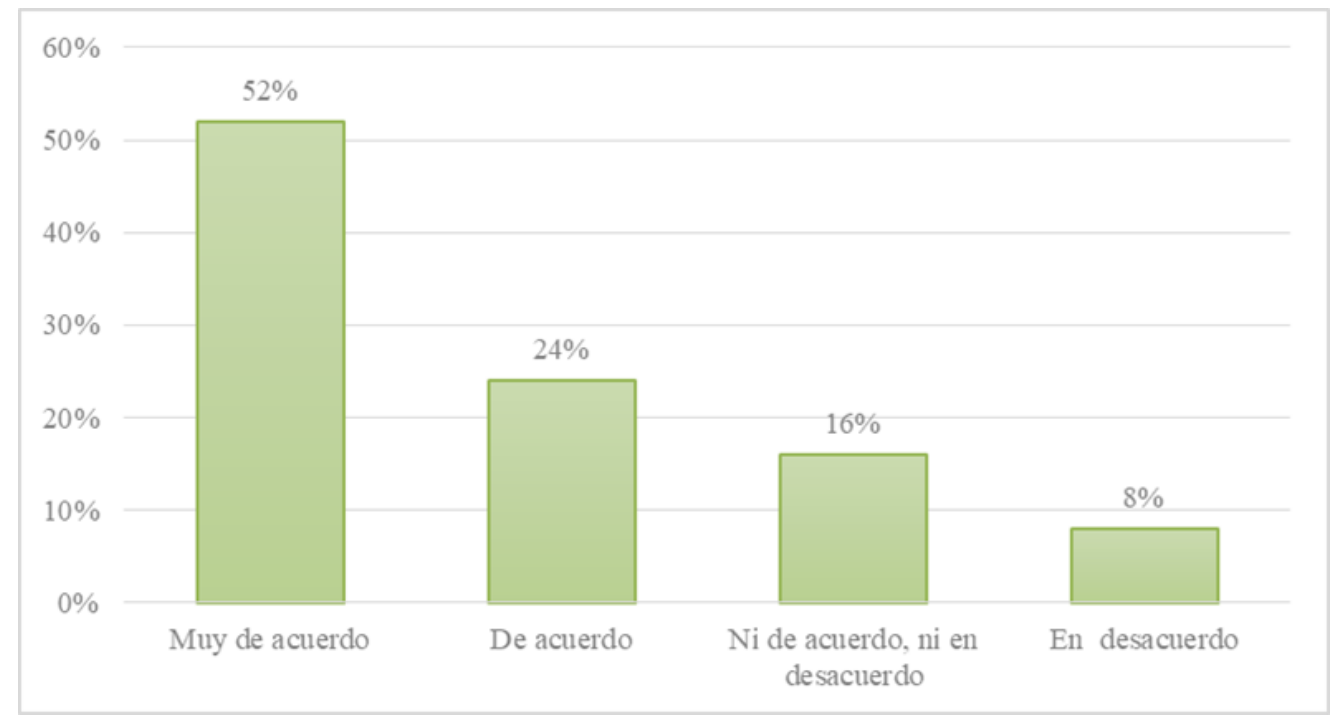

Fuente: Elaboración propia

También se destaca que $76 \%$ de los participantes consideró que las actividades programadas en el curso respondían pertinentemente en pro de los objetivos de aprendizaje, mientras que $16 \%$ no estuvo ni de acuerdo ni en desacuerdo y $8 \%$ consideró que no favorecían a los objetivos de aprendizaje. 

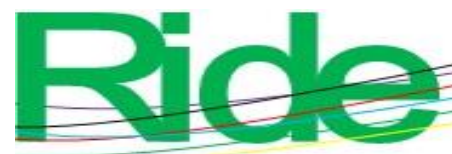

Revista Iberoamericana para la Investigación y el Desarrollo Educativo ISSN 2007 - 7467

Figura 10. Percepción de los docentes sobre el diseño en pro de los objetivos de

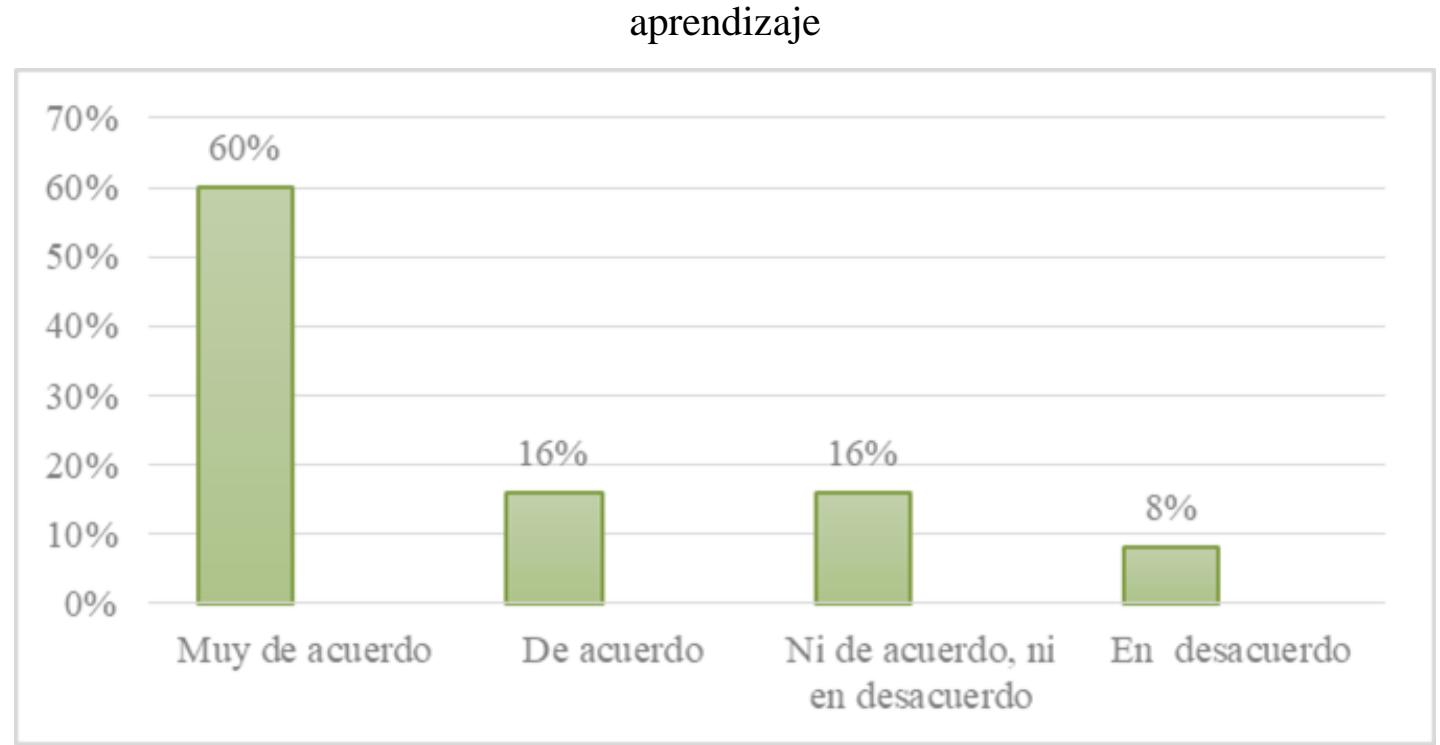

Fuente: Elaboración propia

Asimismo, la pertinencia de las actividades de aprendizaje planificadas como lecturas, trabajo de documentación, investigación, mapas conceptuales, cuadros comparativos, foros y otras fueron consideradas por $84 \%$ de los docentes como favorables para alcanzar los aprendizajes propuestos (figura 11).

Figura 11. Pertinencia de los materiales del curso

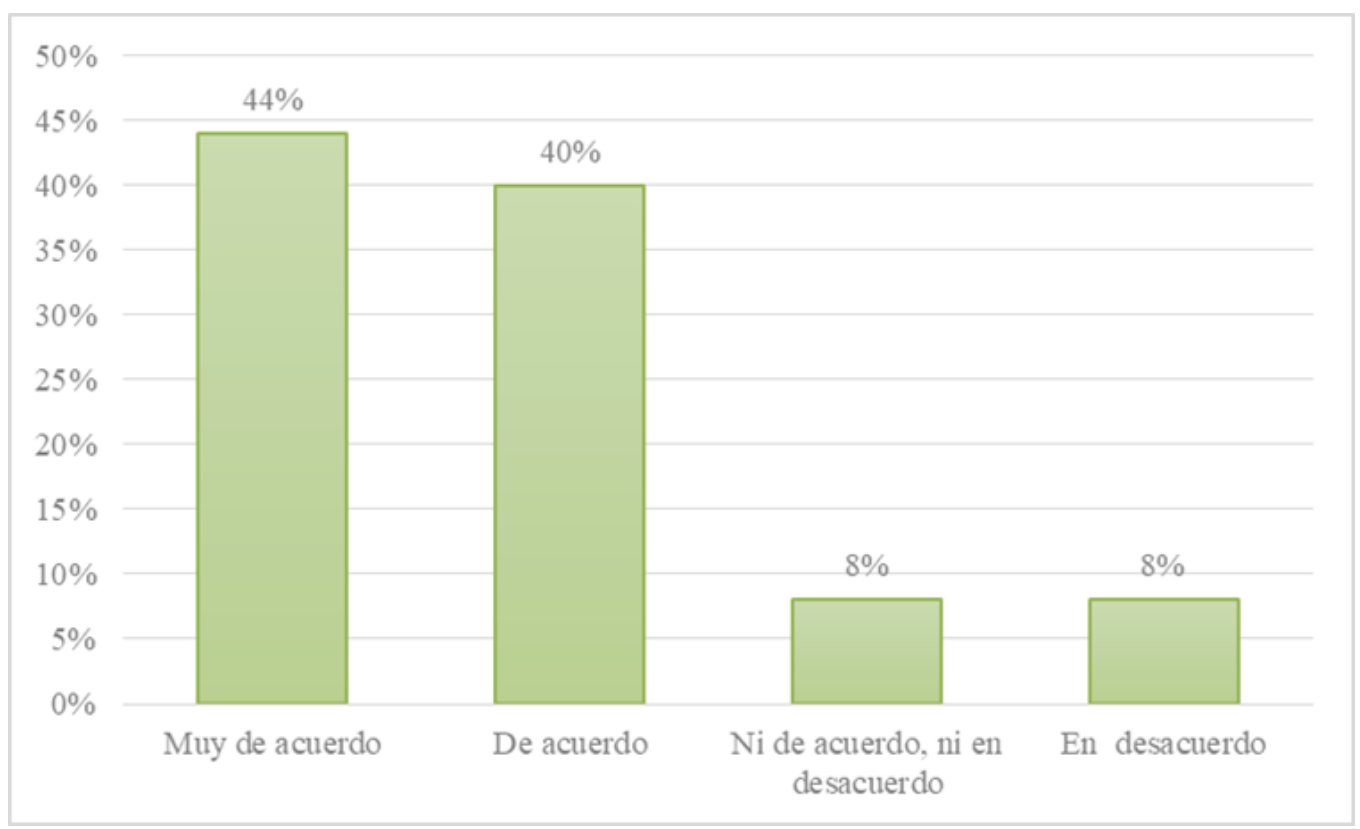

Fuente: Elaboración propia 

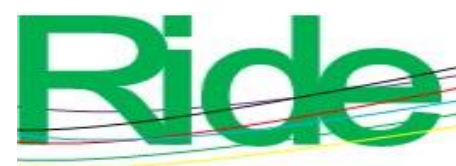

Revista Iberoamericana para la Investigación y el Desarrollo Educativo ISSN $2007-7467$

En relación con las fuentes de información utilizadas para el desarrollo del curso de capacitación, $84 \%$ de los docentes participantes las consideró actualizadas y pertinentes con los contenidos abordados (figura 12).

Figura 12. Percepción de los docentes con relación a la fuente de la información

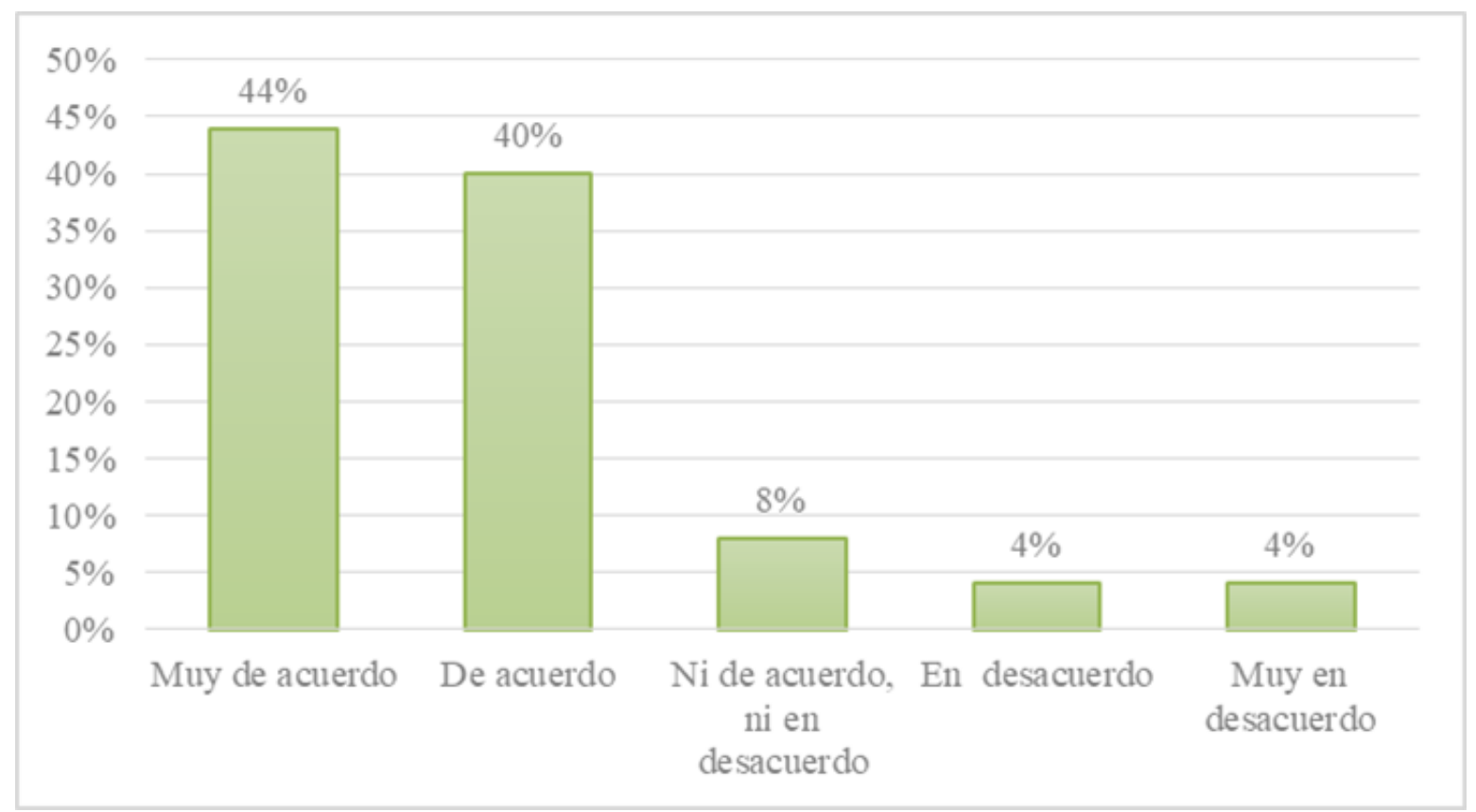

Fuente: Elaboración propia

Se puede apreciar que la percepción del docente con referencia al curso alcanzó un porcentaje medio, menos del que se hubiera gustado tener, sin embargo, se cree que es por la poca familiarización que tienen sobre este tipo de cursos, el adecuado uso de las tecnologías y diferentes herramientas que nos proporcionan esta modalidad. A pesar de desconocer el tema, mostraron actitud de aprender y no se resistieron al cambio para ofrecer una mejor calidad educativa a sus estudiantes. Con estos resultados se dan las pautas para mejorar en próximos proyectos. 


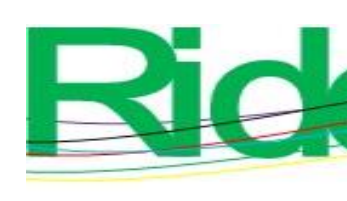

Revista Iberoamericana para la Investigación y el Desarrollo Educativo ISSN $2007-7467$

\section{Discusión}

En este apartado se abordan las ideas con mayor relevancia que se obtuvieron después de aplicar la estrategia didáctica. Como se sabe, llegado a este punto ya se han evaluado los resultados para dar respuesta a la pregunta de investigación, la cual se estableció con el fin de conocer cómo impacta un curso de capacitación docente en un ambiente virtual en torno al TDAH.

Lo que es un hecho es que cada vez son más los niños diagnosticado con TDAH, y debemos tener en cuenta que este transtorno prevalece hasta la edad adulta, por lo tanto, los docentes de educación media superior y superior de la Unacar, en el cumplimiento de las premisas del Modelo Educativo Acalán (Unacar, 2018a), deben estar capacitados para comprender el concepto de inclusión y atender a los alumnos con estas características.

Está investigación tuvo como principal objetivo evaluar el impacto de la capacitación docente diseñada en un ambiente de aprendizaje virtual en relación con el conocimiento y actitud sobre la inclusión y el TDAH.

La variable sobre la actitud en el pretest, y tomando en cuenta las mismas dimensiones que en la primera, se obtuvo como resultado que $36 \%$ de los docentes tenían una actitud adecuada; en la segunda dimensión, tan solo $32 \%$ tenía una actitud adecuada, y en la última dimensión sobre los alumnos con TDAH, $4 \%$ de los docentes mantenía una actitud adecuada. Sevilla, Martín y Jenaro (2018) plantean que el docente siempre se ve influenciado por ciertos factores, genera ciertos conceptos o expectativas, y se predispone en actitud hacia el alumno para trabajar con él, ya que tiende a valorar la capacidad del alumno cuando conoce su entorno comúnmente, o desconocen sobre el trastorno y piensan qué poco se puede hacer por ellos y, en consecuencia, reducen sus expectativas hasta llegar a pensar que únicamente alcanzarán los niveles más bajos esperados.

Después de aplicar la estrategia y llevar a cabo el postest, se arrojaron los siguiente resultados. En la primera dimensión, sobre la inclusión y atención a la diversidad, se obtuvo que $56 \%$ de docentes adquirió una actitud adecuada; en la segunda dimensión, sobre el marco normativo, $76 \%$ de los docente tuvo una actitud adecuada, y en la última dimensión, sobre el TDAH, $66 \%$ de los docentes mostró una actitud adecuada. Con esto se puede dar respuesta a la pregunta de investigación y se puede constatar que el curso diseñado en una ambiente virtual de aprendizaje como estrategia influye significativamente en el proceso de capacitación docente para responder a las demandas actuales de la educación. 


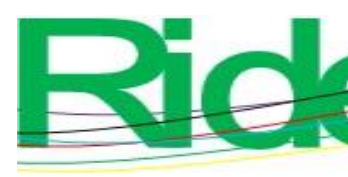

Revista Iberoamericana para la
Investigación y el Desarrollo Educativo
ISSN $2007-7467$

Se evidencia que existe diferencia significativa en la percepción de los docentes con referencia al curso: 80 \% de ellos mostró estar de acuerdo con la presentación del programa al inicio del curso, 84 \% mencionó que la metodología fue presentada en tiempo y forma, $84 \%$ dijo se cumplieron los objetivos planteados del curso, $84 \%$ dijo que hubo una buena interacción entre los participantes y 76 \% consideró que los materiales y actividades fueron pertinentes. No puede pasar por desapercibido que los docentes con mayor edad no están familiarizados con los ambientes virtuales de aprendizaje, por lo tanto, mostraron cierta dificultad, y sin embargo lograron concluirlo. Esta investigación coincide con el trabajo de Trillo (2017), quien plantea que con el uso de una plataforma se obtienen mejoramientos significativos en la adquisición de habilidades y genera un mejoramiento sostenido en la adquisición de aprendizajes y habilidades de pensamiento.

Actualmente, la situación de la educación desafía a los docentes para desarrollar nuevas habilidades, pensamientos y argumentos que implican tomar posición de los nuevos aspectos que implican nuevos retos. Por ello, es importante que la interpretación, análisis, evaluación, explicación y autorregulación sean desarrollados no solo como habilidades por separado. Y esto se logra a través de este curso de capacitación que toma a consideración todos esos aspectos, integrándolos a través del diseño denominado análisis, diseño, desarrollo, implementación y evaluación (ADDIE), lo que permite generar nuevas experiencias significativas de aprendizaje que el docente incorpora en su interior, con la intención de poder ponerlas en acción en el aula.

De igual forma, la mayor parte de los docentes reconoce que, cuando se valora y comprende a los alumnos, se puede tener una actitud positiva que puede servir para mejorar el desempeño de los alumnos. Y que este tema debería incluirse en la actualización/capacitación docente.

Finalmente, las limitaciones que se identificaron en el estudio se centran en el interés inicial que tienen los profesores de nivel superior para capacitarse en el manejo de herramientas que permitan el manejo y trabajo con los estudiantes con TDAH. Posterior a la capacitación, como se ha externado, los participantes han cambiado su actitud en relación con el tema. Sin duda existe una necesidad creciente de capacitar a los profesores de nivel superior debido al número cada vez más mayor de estudiantes con este trastorno que están llegando a realizar estudios superiores. 


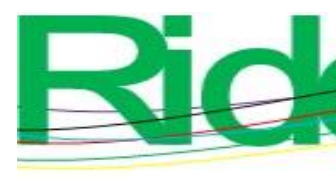

Revista Iberoamericana para la Investigación y el Desarrollo Educativo ISSN 2007-7467

\section{Conclusiones}

Se recomienda implementar muchas más estrategias de concientización a toda la comunidad universitaria. Contar con la actualización constante de los docentes para brindar un servicio igualitario y de educación de calidad a los estudiantes con condiciones de vida diferentes y así lograr una educación para la diversidad.

Dentro de los comentarios sobre la pertinencia del curso, uno fue sobre el tiempo que se dio para realizar las actividades, ya que muchos mencionaban que por la carga de trabajo se les complicaba un poco realizarlas y entregarlas a tiempo. De igual manera, se sugiere tomar en cuenta la complejidad de las tareas y la claridad de las instrucciones. Esto se puede considerar para otros cursos de capacitación docente. Se debe considerar que los docentes deben ser conscientes de su labor, que sean creativos, que busquen nuevas estrategias y metodologías. Que se oriente y acompañe a los docentes con un programa para la inclusión y atención a la diversidad, tomando en cuenta las diferentes necesidades de los

alumnos que se presentan dentro de las aulas, y que sea un trabajo en equipo, con responsabilidad.

Con base en lo investigado, es necesario que todos los profesionales que estén relacionados con la educación de este país, en todos sus niveles, desde el básico hasta medio superior y superior, se capaciten y actualicen con referencia al tema de la inclusión y atención a la diversidad, ya que cada vez son mayores los casos que se presentan en las escuelas, y para que se pueda cumplir con los parámetros del Programa Sectorial de Educación (Diario Oficial de la Federación [DOF], 13 diciembre de 2013) se requiere de profesionales con los conocimientos y actitudes suficientes para atender adecuadamente a sus alumnos, y ofrecer así una educación de calidad para todos. De esta forma, se atienden dos de los objetivos de dicho programa, los cuales plantean el fortalecimiento de la calidad y pertinencia de la educación media superior, superior y de la formación para el trabajo, con el fin último de contribuir al desarrollo de México a través de una mayor cobertura, inclusión y equidad educativa entre la población en pro de la integración de una sociedad más justa (DOF, 13 diciembre de 2013).

Los ambientes virtuales de aprendizaje sin duda son una herramienta que abre muchas oportunidades de capacitación para el docente, ya que la hace más atractiva e interesante, además de estar siempre disponible, lo que permite que se acomode a sus tiempos, ya que puede marcar sus propias pautas de estudio y puede interactuar con una 

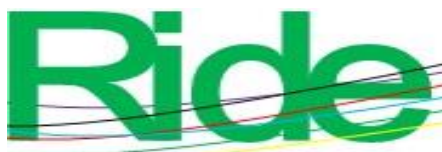

variedad de personas de distintos lugares, países y culturas que tienen un interés común en un ámbito en concreto. Abre también la posibilidad que se puedan abarcar diversos temas de interés que protagonizan hoy en día la educación de nuestro país.

Es importante también que la política educativa o las instituciones incentiven la incorporación de los cursos en un ambiente virtual de aprendizaje, el mejoramiento de las redes y el servicio de Internet, así como los soportes necesarios y que no surjan complicaciones a la hora de llevarlos a cabo. Sobre el modelo instruccional ADDIE, podemos decir que es importante llevar un control sobre cada procedimiento para no cometer errores que puedan verse reflejados al momento de la implementación del curso. También es trascendental llevar a cabo el registro de la rúbrica o los instrumentos de evaluación que se hayan determinado para la evaluación formativa como sumativa para cerciorarse de que todas las actividades o procesos realizados cumplan con los objetivos del curso propuesto. 


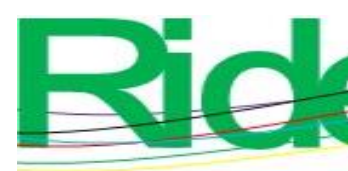

Revista Iberoamericana para la Investigación y el Desarrollo Educativo ISSN $2007-7467$

\section{Referencias}

Cabrera, D. M. (2018). Calidad educativa, discurso y poder en Educación Superior. Atenas, 1(41), 198-212.

Diario Oficial de la Federación [DOF]. (13 diciembre de 2013). Programa Sectorial de Educación. 2013-2018. Diario Oficial de la Federación. Recuperado de http://www.dof.gob.mx/nota_detalle.php?codigo=5326569\&fecha=13/12/2013.

García, S. R., Jaña, C. M. y Yáñez, C. G. (2019). Modelo de seguimiento basado en TIC de la formación continua de profesores. RUNAE, 66-88 Recuperado de http://www.runae.info/index.php/RUNAE/article/view/40.

Hernández, R., Fernández, C. y Baptista, P. (2010). Metodología de la investigación (5. ${ }^{a}$ ed.). México: McGraw-Hill Interamericana.

Herrera, S., Guzmán, M., Salinas, H., Sánchez, N. y Díaz, J. (2018). Inclusión educativa desde la perspectiva del estudiante de educación. Revista Boletín Redipe, 7(7), 187198. Recuperado de http://revista.redipe.org/index.php/1/article/view/533.

Ibarra, S., Segredo, S., Juárez, L. G. y Tobón, S. (2018). Estudio de validez de contenido y confiabilidad de un instrumento para evaluar la metodología socioformativa en el diseño de cursos. Revista ESPACIOS, 39(53).

Instituto Nacional de Estadística y Geografía [Inegi]. (2010). Censo de Población y Vivienda 2010. México: Instituto Nacional de Estadística y Geografía

Martín, T. D., Latorre, A. A., Herrero, I. L., Forcén, P. L. y Oliver, M. P. (2018). Diseño y análisis estadístico de un instrumento dirigido a evaluar el Trastorno por déficit de atención e hiperactividad en población infanto-juvenil. European Journal of Child Development, Education and Psychopathology, 6(2), 89-95.

Muñiz, J. y Fonseca, E. (2019). Diez pasos para la construcción de un test. Psicothema, 31(1).

Quero, M. (2010). Confiabilidad y coeficiente Alpha de Cronbach. Telos, 12(2), 248-252

Secretaría de Educación Pública [SEP]. (2012). Programa de Fortalecimiento de la Educación Especial y de la Integración Educativa. México: Secretaría de Educación Pública. Recuperado de https://www.educacionespecial.sep.gob.mx/pdf/tabinicio/2012/datos_pfeeie_2012.p df. 


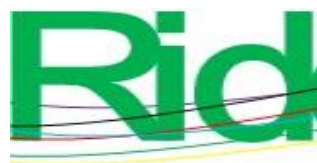

Revista Iberoamericana para la
Investigación y el Desarrollo Educativo
ISSN $2007-7467$

Sevilla, D. E., Martín, M. J. y Jenaro, C. (2018). Actitud del docente hacia la educación inclusiva y hacia los estudiantes con necesidades educativas especiales. Innovación Educativa, 18(78), 115-141.

Sierra, A., Negron, J. C. y Santoyo, S. P. (2017). Evaluación psicológica integral en estudiantes universitarios. Praxis Investigativa ReDIE: Revista Electrónica de la Red Durango de Investigadores Educativos, 9(17), 20-30.

Trillo, C. M. (2017). Construcción y validación de la escala de detección de conductas autistas. (tesis de maestría). Universidad de San Martín de Porres, Lima. Recuperado de http://repositorio.usmp.edu.pe/handle/usmp/3081.

Universidad Autónoma del Carmen [Unacar]. (2018a). Modelo Educativo Acalán 2017 (1. ${ }^{a}$ ed.). Campeche, México: Universidad Autónoma del Carmen.

Universidad Autónoma del Carmen [Unacar]. (2018b). Plan de Desarrollo Institucional 2017 - 2021. Campeche, México: Universidad Autónoma del Carmen.

Vergara, A. (Diciembre, 2007) Desafíos del E-learning para la formación continua de profesores. Revista Pensamiento Educativo, 41(2), 101-114. Recuperado de http://bibliorepo.umce.cl/libros_electronicos/magister/mag_19.pdf\#page=102. 


\begin{tabular}{|l|l|}
\hline Rol de Contribución & Autor (es) \\
\hline Conceptualización & Gabriela Guadalupe Montiel Cantarell \\
\hline Metodología & Juan José Díaz Perera \\
\hline Software & Juan José Díaz Perera \\
\hline Validación & $\begin{array}{l}\text { Gabriela Guadalupe Montiel Cantarell 50\%, Sergio Jiménez } \\
\text { Izquierdo 25\%, Melenie Guzmán Ocampo 25\% }\end{array}$ \\
\hline Análisis Formal & Juan José Díaz Perera \\
\hline Investigación & $\begin{array}{l}\text { Heidi Angélica Salinas Padilla 50\% y Gabriela Guadalupe } \\
\text { Montiel Cantarell 50\% }\end{array}$ \\
\hline Recursos & $\begin{array}{l}\text { Claudia Mariel (Responsable Superación Académica } \\
\text { Institucional) }\end{array}$ \\
\hline Curación de datos & Heidi Angélica Salinas Padilla \\
\hline $\begin{array}{l}\text { Escritura - Preparación del } \\
\text { borrador original }\end{array}$ & $\begin{array}{l}\text { Heidi Angélica Salinas Padilla 50\% y Gabriela Guadalupe } \\
\text { Montiel Cantarell 50\% }\end{array}$ \\
\hline $\begin{array}{l}\text { Escritura - Revisión y } \\
\text { edición }\end{array}$ & $\begin{array}{l}\text { Heidi Angélica Salinas Padilla 50\%, Cynthia Daniela Álvarez } \\
\text { 25\% }\end{array}$ \\
\hline Visualización & Juan José Díaz Perera \\
\hline Supervisión & Heidi Angélica Salinas Padilla \\
\hline Adquisición de fondos & Angélica Salinas Padilla 50\% y Juan José Díaz Perera \\
\hline
\end{tabular}

